\title{
Novel Three-Dimensional (3D) Carbon-Metal- Polymeric framework: Efficient removal of Chemical and Biological Contaminants
}

\section{Sasidharan Venkataramanan}

BS Abdur Rahman Institute of Science and Technology, Chennai, India

\section{Deepa Sachan}

Indian Institute of Technology Guwahati, Guwahati-781039 (India)

\section{Divya Chauhan}

University of South Florida

Neetu Talreja

University of La Serena

Mohammad Ashfaq ( $\nabla$ mohdashfaqbiotech@gmail.com )

BS Abdur Rahman Institute of Science and Technology, Chennai, India

\section{Research Article}

Keywords: 3D-materials, polymer, metal nanosheet, contaminants, graphene

Posted Date: February 9th, 2021

DOI: https://doi.org/10.21203/rs.3.rs-168328/v1

License: (9) This work is licensed under a Creative Commons Attribution 4.0 International License. Read Full License

Version of Record: A version of this preprint was published at Scientific Reports on April 8th, 2021. See the published version at https://doi.org/10.1038/s41598-021-86661-w. 
Novel Three-Dimensional (3D) Carbon-Metal-Polymeric framework: Efficient removal of Chemical and Biological Contaminants

Sasidharan Venkataramanan ${ }^{1}$, Deepa Sachan $^{2}$, Divya Chauhan ${ }^{3}$, Neetu Talreja ${ }^{4}$, Mohammad $\operatorname{Ashfaq}^{1 *}$

${ }^{1}$ School of Life Science, BS Abdur Rahaman Institute of Science and Technology, Chennai, India

${ }^{2}$ Center for the Environment, Indian Institute of Technology Guwahati, Guwahati-781039 (India)

${ }^{3}$ Department of Chemical and Biomedical Engineering, University of South Florida, USA

${ }^{4}$ Multidisciplinary Research Institute for Science and Technology, IIMCT, University of La Serena, 1015 Juan Cisternas St., La Serena, Chile.

Corresponding author: mohdashfaqbiotech@gmail.com (Mohammad Ashfaq) 


\section{Abstract}

The continuously increasing existence of contaminants such as chemical and biological mainly dye, bacteria, and heavy metals ions in water bodies has increased environmental concern due to their hostile effects on living things. Therefore, it the necessity to be developing newer material that skirmishes such environmental menace. The present works focus on the synthesis of a novel three-dimensional (3D) polymer-metal-carbon (3D-PMC) framework for the exclusion of contaminants (chemical and biological) from water bodies. Initially, polyurethane (PU) foam was treated with nitric acid and used as a scaffold for the development of 3D-PMC. The copper nanosheet $(\mathrm{Cu}-\mathrm{NS})$ were deposited on to the functionalized PU foam to produce $\mathrm{Cu}-\mathrm{NS}-\mathrm{PU}$ material. The mechanically exfoliated graphene and mixed with chitosan to produce a graphenechitosan homogenous suspension. The produce homogenous suspension was deposited Cu-NS-PU for the development of the 3D-PMC framework. The prepared 3D-PMC framework was characterized by scanning electron microscopy (SEM), Energy Dispersive X-Ray Analysis (EDX), Fourier-transform infrared spectroscopy (FT-IR), and X-rays diffraction (XRD) analysis. The prepared 3D-PMC framework was subjected to various adsorption parameters to assess the sorption ability of the material. The prepared 3D-PMC framework was effectively used for the removal of chromium $(\mathrm{Cr})$ metal ions and Congo-red (CR) dye from the water system. The synthesis of the 3D-PMC framework is simple, novel, cost-effective, and economically viable. Therefore, the prepared 3D-PMC framework has the potential to be used as a filter assembly in water treatment technologies.

Keywords: 3D-materials, polymer, metal nanosheet, contaminants, graphene 


\section{Introduction}

The incessant increasing occurrence of biological and chemical pollutants such as heavy metal ions (HMI), dyes, and biological contamination (bacteria and fungi) in the water system increased the environmental menace globally. Contamination of water bodies by toxic HMI such as chromium $(\mathrm{Cr})$, arsenic $(\mathrm{As})$, lead $(\mathrm{Pb})$, cadmium $(\mathrm{Cd})$, and mercury $(\mathrm{Hg})$ is one of the solemn threats globally due to their high toxicity to living being including human health. The existence of pollutants in water bodies has increased environmental worry worldwide due to its adverse effects on animals, plants as well as human health ${ }^{1-6}$.

Textile industrial waste mainly contains various pollutants like alkalis, inorganic and organic salts, dye, and HMI. $\mathrm{Cr}(\mathrm{VI})$ is extensively used for the leather dyeing procedure. Moreover, high solubility in water makes it easier to enter the food chains, thereby higher accumulation within the body that leads to severe health issues. The incessant exposure of $\mathrm{Cr}(\mathrm{VI})$ to a human might because damaging various organs like the liver, kidney, and improper functioning of the circulatory and nervous system. Congo Red (CR) dye is a recognized pollutant and highly toxic and cancerous. Gram-negative (Escherichia coli (E. coli)), and Gram-positive (Staphylococcus aureus (S. aureus)) bacterial strains some of the most prevalent bacteria in water. Biological contamination is one of the major issues nowadays that developed various healthrelated problems such as diarrhea, cholera, and bacterial infectious disease ${ }^{7-12}$. In this context, treatment or confiscation of such contaminants (both chemical and biological) is necessary for pure drinking water.

Numerous processes mainly physical, chemical, and biological treatment has been used to treat all contaminants from water. However, these processes are efficient for the confiscation of either chemical or biological pollutants from water bodies. Hence, there is a necessity to be 
developed newer competent, economically viable adsorbent materials or filters that might be eliminated chemical and biological contaminants from the water stream ${ }^{13-16}$. In this context, polymeric composite contains different surface functional groups that efficiently remove various contaminants from water.

Numerous polymers such as polyvinyl alcohol (PVA), chitosan, poly (methyl methacrylate) (PMA), poly-aniline, poly-pyrrole, poly-urea, poly-urethane have been used to a developed adsorbent or filter materials for the confiscation of a pollutant from water. However, high swelling ability and low affinity of adsorbent or filter materials towards contamination remain a concern ${ }^{17-}$ ${ }^{21}$. In this context, hybrid materials or a combination of more than two or three materials might be overcome such associated issues with high removal efficiency.

Chitosan has considered necessary filtration characteristics. Moreover, Chitosan is a nontoxic, biocompatible, biodegradable polysaccharide, extraordinary adsorbing ability towards anionic dyes like CR-dye, and exceptional antibacterial ability, thereby extensively used in numerous filtration applications (water to air purification) ${ }^{21-23}$. Carbon-based nanomaterials such as CNTs, CNFs, graphene, and graphene oxide exhibit a promising role in the cleansing of pollutants from water bodies. Graphene is considered a futuristic material due to its exceptional characteristics like large specific surface area, and easily tunable properties according to the specific applications ${ }^{24-26}$. Therefore, graphene becomes a suitable candidate for the confiscation of contaminants from water.

Metal-NPs mainly $\mathrm{Ag}, \mathrm{Au}, \mathrm{Zn}$, and $\mathrm{Cu}$ extensively used to treat biological pollutants like bacteria and fungi that inhibit the synthesis of protein, disruption of cells, and damaging DNA, thereby inhibit or kill microorganisms. The nano-sized $\mathrm{Cu}-\mathrm{NPs}$ have the tremendous quality to clean out chemical as well as biological waste due to high reactivity ${ }^{12,27,28}$. The unique 
combination of all these materials makes a suitable candidate for the development of PMC based adsorbent or filter materials.

The proposed method of development of PMC framework based filter or adsorbent is simple, novel, and economically viable, and efficiently remove both chemicals as well as biological contaminants from water. The prepared PMC scaffold was used for the confiscation of contaminants from water and proposed as the filter or adsorbent materials. The graphene and chitosan-coated on the PU-foams enhanced the efficiency of the filter or adsorbent materials towards both biological and chemical contaminants. $\mathrm{Cu}-\mathrm{NS}$ deposited on the PU-foams enhances the antibacterial activity of the composite and formed a complex with HMI. Further, amide and carboxylate groups of chitosan of the composite facilitate adsorption of dye, heavy metal ions, and kill biological contaminants, thereby enhancing the sorption ability against both chemical and biological contaminants. The novelty is in the simplistic development of the low-cost polymermetal-carbon based materials as the efficient adsorbent materials or filters for the confiscation of both chemical and biological pollutants from water or purification of water. The different components of the adsorbent or filter material, namely, PU foam, $\mathrm{Cu}-\mathrm{NS}$, graphene, and chitosan, serve different purposes. The Cu-NS serves dual roles. (1) Facilitate the antibacterial activity or removal of biological contaminants, and (2) Facilitate the adsorption ability of Cr(VI) and CR-dye from water. PU foam serves dual roles. (1) Acts as the framework for the development of PMC materials, and (2) It provides interconnecting pores within the polymeric composite, thereby increasing the exposure of CU-NS and Chitosan to $\mathrm{Cr}(\mathrm{VI})$ and CR-dye. Chitosan serves triple roles. (1) It provides stability to the $\mathrm{Cu}-\mathrm{NS}$ against leach out or rapid dissolution from PMC material, (2) Facilitate antibacterial activity or removal of biological contaminants from water, and (3) Enhance the sorption capacity of the $\mathrm{Cr}(\mathrm{VI})$ and CR-dye from water. Graphene enhances the 
sorption ability of the $\mathrm{Cr}(\mathrm{VI})$ and $\mathrm{CR}$-dye from water. The unique combination of the polymertransition metal-carbon composite dispersed with $\mathrm{Cu}-\mathrm{NS}$ and graphene yielded the efficient adsorbent or filter material, used to remove both chemical and biological contaminants from water or provide pure water. The produced PMC materials were highly capable to remove $\mathrm{Cr}(\mathrm{VI}), \mathrm{CR}$ dye, and bacterial contaminants from water. The method of synthesizing the PMC materials or polymer-transition metal-carbon-composite adsorbent or filter material in the present study is novel, facile, and economically viable.

\section{MATERIALS AND METHOD}

\subsection{Materials}

Chitosan, ammonia, acetic acid, graphite powder, polyurethane foam, nitric acid, chromium (VI), copper sulfate, Congo red (CR) dye, hydrochloric acid, sodium hydroxide, deionized (DI) water.

\subsection{Preparation PMC adsorbent materials}

The synthesis of the Cu-NS deposited Pu-foam-graphene-chitosan based scaffold or PMC filter or adsorbent material was started with chemical treatment of PU-foams using $1 \mathrm{M} \mathrm{HNO}_{3}$ to produce chemically-treated PU-foams. The produce chemically-treated PU-foams washed several times using DI water until the surface becomes neutral $(\mathrm{pH} \sim 7)$. Next, $\mathrm{Cu}-\mathrm{NS}$ was synthesized by CBD process, for this $0.2 \mathrm{M} \mathrm{CuSO}_{4}$ was dissolved in $150 \mathrm{~mL}$ of DI water to produce a homogenous suspension. Approximately, $15 \mathrm{~mL}$ of $\mathrm{NH}_{3}$ solution was added in the homogenous suspension of $\mathrm{CuSO}_{4}$ to maintain the $\mathrm{pH}$ value of $\sim 10-11$. The homogenous suspension was kept in the water bath at $90{ }^{\circ} \mathrm{C}$ after 15 min treated PU-foam was dipped into the homogenous suspension for a different time interval (30-240 $\mathrm{min})$ to synthesize PU-Cu-NS. The maximum deposition was 
observed at 180-240 min of Cu-NS on to the PU-foam. For dense growth or higher deposition of $\mathrm{Cu}-\mathrm{NS}$, we optimize 240 min of incubation time to prepare PU-Cu-NS samples. After deposition of $\mathrm{Cu}-\mathrm{NS}$ onto the PU-foam, samples were dried at $80^{\circ} \mathrm{C}$ for $24 \mathrm{~h}$, and then samples were washed gently to remove excessive on bonded $\mathrm{Cu}-\mathrm{NS}$ on to the PU-foam. Next, washed PU-Cu-NS samples were dried at $80{ }^{\circ} \mathrm{C}$ for $24 \mathrm{~h}$. The developed PU-Cu-NS samples were used for the preparation of PMC based adsorbent or filter materials.

The graphene was synthesized from graphite powder using a mechanical exfoliation process. Approximately $0.5-1.5 \mathrm{~g}$ of chitosan granules were dissolved in $120 \mathrm{~mL}$ of DI water with the help of continuous stirring and heating at $90{ }^{\circ} \mathrm{C}$ for $60 \mathrm{~min}$. Next, $0.05 \%$ acetic acid was added into the chitosan solution to produce a homogenous solution of chitosan. Approximately, 0.1 to 0.5 g of mechanically exfoliated graphene was added into the homogenous solution of chitosan using continuous stirring at $300 \mathrm{rpm}$ for $2 \mathrm{~h}$ at room temperature $\left(\sim 30{ }^{\circ} \mathrm{C}\right)$ to produce a chitosangraphene homogenous solution. The produce chitosan-graphene homogenous solution used as an encapsulating agent for PU-Cu-NS samples by continuously stirring at $200 \mathrm{rpm}$ for $2 \mathrm{~h}$ to produce PMC based adsorbents or filter materials. The developed 3D-PMC framework was used as a filter or adsorbent materials for the confiscation of all contaminants from water. Figure. 1 shows a schematic illustration of the synthesis of a PMC framework used as the filter or adsorbent materials for environmental remediation application.

\subsection{Batch adsorption studies}

A batch experiment was performed to analyze different influential factors such as time of adsorption, concentration, $\mathrm{pH}$ and temperature over adsorption of $\mathrm{Cr}(\mathrm{VI})$ onto PMC framework material. Adsorption kinetics was studied at $150 \mathrm{mgL}^{-1}$ of $\mathrm{Cr}(\mathrm{VI})$ and $10 \mathrm{mgL}^{-1} \mathrm{CR}$ using $10 \mathrm{mg}$ 
PMC with different time intervals from $0-24$ hrs at a constant speed of $100 \mathrm{rpm}$ at $35^{\circ} \mathrm{C} . \mathrm{pH}$ study on $\mathrm{Cr}(\mathrm{VI})$ and $\mathrm{CR}$ using PMC was performed to analyze the better absorbance efficiency (mg/L). Solution $\mathrm{pH}$ was adjusted by adding $1 \mathrm{~N} \mathrm{HCl}$ and $1 \mathrm{~N} \mathrm{NaOH}$ to maintain the $\mathrm{pH}$ range (2 to 9), while the adsorbent dose, temperature, and other parameters were kept constant. A stock solution of $1000 \mathrm{mgL}^{-1}$ of $\mathrm{Cr}(\mathrm{VI})$ and $\mathrm{CR}$ was prepared. The test solutions of $25 \mathrm{~mL}$ volume having different adsorbate concentrations were prepared in conical flasks from the stock solution. A small amount ( $\sim 0.01 \mathrm{~g}$ ) of the prepared PMC was transferred to the conical flasks. The flasks containing the test solution and adsorbents were kept in a mechanical shaker $(150 \mathrm{rpm})$ at room temperature $\left(35{ }^{\circ} \mathrm{C}\right)$. The concentration of $\mathrm{Cr}(\mathrm{VI})$ in the solution was ascertained by using 1,5diphenylcarbazide (DPC) method while CR was measured directly using a UV-VIS spectrophotometer. The wavelength of the detector was set at $540 \mathrm{~nm}$ and $496 \mathrm{~nm}$, respectively. From the species balance equation, the amount of $\mathrm{Cr}(\mathrm{VI})$ and $\mathrm{CR}$ adsorbed by the prepared materials was calculated.

$$
q=V(C i-C e) / W
$$

where $q$ is the loading $\left(\mathrm{mg} \mathrm{g}^{-1}\right)$ of $\mathrm{Cr}(\mathrm{VI})$ and $\mathrm{CR}$ and $\mathrm{Ci}$ and $\mathrm{Ce}$ are the initial and final (equilibrium) concentrations $(\mathrm{mg} / \mathrm{L})$, respectively, of the solution. $V$ is the volume (L) of the solution and $W$ is the weight (g) of the adsorbent.. All tests were done in triplicates to check reproducibility

\subsection{Antibacterial analysis}

The antibacterial test analysis of the PMC based adsorbent materials was determined against both E. Coli, and S. aureus. The bacterial strains were cultured in a Luria Bertani broth (LB media) medium and incubate at $37^{\circ} \mathrm{C}$ for $24 \mathrm{~h}$ in a bacterial incubator. Different doses $(100,200,400$, and 
$600 \mathrm{mg}$ ) of PMC based adsorbent materials were analyzed by using the plate count method. $1 \mathrm{~mL}$ of bacterial strains was mixed into $50 \mathrm{~mL}$ of phosphate buffer saline (PBS) solution with different amounts of PMC based adsorbent materials in a conical flask. The initial bacterial count was $\sim 10^{4}$ $10^{5} \mathrm{CFU} / \mathrm{mL}$. Approximately, $100 \mu \mathrm{L}$ incubated bacterial samples were taken from each conical flask and spread over the LB agar medium plate and then incubated at $37^{\circ} \mathrm{C}$ for $24 \mathrm{~h}$. The bacterial culture without PMC based adsorbent materials served as the control for comparison purposes. All experiments were performed in triplicate to check reproducibility.

\section{Material Characterization}

The surface structure of the prepared PMC based adsorbent materials was characterized by using several characterization techniques such as field emission-scanning electron microscopy (FESEM), Energy dispersive X-rays (EDX), X-ray diffraction (XRD), and Fourier transform-infrared (FT-IR) spectroscopy. The surface texture of the prepared PMC based adsorbent materials was characterized by using FE-SEM (MIRA3-, TESCAN, A.S., Brno, Czech Republic). The presence of $\mathrm{Cu}-\mathrm{NS}$ within the PMC based adsorbent materials was observed by using EDX analysis (Oxford, Inc., Germany). The crystalline pattern of the PMC based adsorbent materials was determined using XRD analysis with $\mathrm{Cu}$ Ka radiation $\left(\mathrm{k}=1.54178 \mathrm{~A}^{\circ}\right)$ at a scan rate of $5{ }^{\circ} \mathrm{C}$ per min. The surface functional group of the prepared PMC based adsorbent materials was ascertained by FTIR spectra with a wavelength range $\left(400-4000 \mathrm{~cm}^{-1}\right)$ (Brucker, Germany). 


\section{Result and discussion}

\subsection{SEM and EDX analysis}

Figure. 2(a) shows the SEM images of PU foam. PU foam consists of several macropores. As observed from the SEM image, the size of pores varies from 150 to $500 \mu \mathrm{m}$ that uniformly distributed over the entire foam. The interconnecting pores through a thin boundary create a framework. Figure. 2(b) shows the nanosheet like the structure of mechanically exfoliated graphene. Multi-layer graphene can be seen from the images with sharp edges. Fig. 2(c-c') shows images of Cu-NS-PU. As observed from the figure, Cu-NS uniformly deposited over the entire surface of PU foam. The magnified SEM image shows Cu-NS deposited on to the surface of PU foam. Fig. 2(d-d') shows the SEM images of PMC samples, chitosan encapsulated on Cu-NS-PU can be observed from the images. The encapsulation of chitosan might decrease the $\mathrm{Cu}$ leach out from the PU surface. Also, it enhances the sorption ability of dyes and heavy metal ions as well as antibacterial activity ${ }^{29,30}$. Moreover, interconnecting pores might be beneficial for higher adsorption loading of contaminants, discuss later in the manuscript.

Figure. 3 (a-b) shows the elemental analysis and elemental mapping of the Cr(VI) adsorbed PMC samples. The presence of Cr content in the PMC samples attributed to the adsorption of $\mathrm{Cr}(\mathrm{VI})$ on the PMC sample. Moreover, approximately $55 \%$ of $\mathrm{Cr}$ (VI) indicated a higher sorption ability over the PMC based material.

\subsection{XRD analysis}

The XRD diffraction pattern of Cu-NS-PU was shown in Figure 4. All the diffraction peaks were well matched with the solo PU, Chitosan, graphene, and $\mathrm{Cu}$ of $\mathrm{Cu}-\mathrm{NS}-\mathrm{PU}$. As shown in Figure, Chitosan had a typical sharp peak at $10^{\circ}$. A broad peak appeared in the pattern at $19.25^{\circ}$ and 
23.28 was observed for the PU sponge. A characteristic peak of graphene was observed at $26^{\circ}$. The $\mathrm{Cu}$ diffraction pattern was observed at $2 \theta 45^{\circ}, 50.6^{\circ}$ and $74.9^{\circ}$ which correspond to the crystallographic indices of the (111), (200) and (220), respectively, which proves that sample contained $\mathrm{Cu}$ in its pure metallic FCC phase (JCPDS No. 4-836) ${ }^{31-33}$. These results indicate that one-step loading of $\mathrm{Cu}-\mathrm{NS}$ over PU was successfully done to develop Cu-NS-PU, which allows the function of graphene to be well dispersed and attached to the reticulated matrix of PU sponge to prepared PMC based adsorbent material.

\subsection{FT-IR analysis}

Figure. 5 shows the FT-IR spectra of the various constituents of the PMC based materials. The spectra are shown for the PU foam, Cu-NS-PU, and PMC material. The peaks observed at 1241, $1530,1655,1730,2978,2923,3315$, and $3382 \mathrm{~cm}^{-1}$ in the PU foam sample are assigned to -C-O, $\mathrm{N}-\mathrm{H}, \mathrm{C}=\mathrm{C}, \mathrm{C}=\mathrm{O}, \mathrm{C}-\mathrm{H}, \mathrm{C}-\mathrm{H}, \mathrm{N}-\mathrm{H}$, and $\mathrm{N}-\mathrm{H}$, respectively ${ }^{34}$. All characteristic peaks were observed in the Cu-NS-PU sample except 1241, $2978 \mathrm{~cm}^{-1}$. Moreover, the intensity of all characteristic peaks decreased in the $\mathrm{Cu}-\mathrm{NS}-\mathrm{PU}$ sample compare with that of the PU foam sample due to the $\mathrm{Cu}$ NS deposition on the surface of PU foam ${ }^{35}$. All characteristics peaks were observed in PMC materials. Some new characteristics peaks at 1050, 1550, 1640, 1657, and $3490 \mathrm{~cm}^{-1}$ in the PMC sample are assigned to be $\mathrm{P}=\mathrm{O}$ stretching of a phosphate group, $\mathrm{NH}_{2}$, amide band $\mathrm{I}$, and $\mathrm{NH}_{2}$ and OH group, respectively that belongs to chitosan ${ }^{36}$. The FT-IR spectra confirm that the PMC material was successfully synthesized. These functional groups aided advantageous to adsorb chemical contaminants as well as remove biological contaminants. 


\subsection{Adsorption study}

\subsubsection{Kinetics study}

Kinetics experiment was performed to study the rate of adsorption of $\mathrm{Cr}$ (VI) and CR-dye, at 150 and $10 \mathrm{ppm}$, respectively, in the time range of 10-1440 min. As observed from the Figure, the adsorption of $\mathrm{Cr}$ (VI) and CR-dye on PMC material was rapid during the initial $8 \mathrm{~h}$, after approaching the equilibrium concentration $(24 \mathrm{~h})$, the rate slowed down. Pseudo-second-order kinetic models were used to explain the uptake of $\mathrm{Cr}(\mathrm{VI})$ and $\mathrm{CR}$ dye with time. The model equation was explained as follows-

$$
\frac{1}{k q e}+\frac{t}{q e}=\frac{t}{q t}
$$

Where qe is the equilibrium adsorption loading, and qt is the adsorption capacity (loading) at time $\mathrm{t}$ and $\mathrm{k}$ is the rate constant. Figure 6 and Table. 1, describes the kinetic model and respective parameters as per Eq (2) fitted to the data. The numerical value of the rate constant $\mathrm{k}$ calculated from the intercept of the line, respectively, was 0.0076 and $0.087 \mathrm{~g} / \mathrm{mg} \mathrm{h}^{-1}$ for $\mathrm{Cr}(\mathrm{VI})$ and CR dye, respectively. The relatively higher $\mathrm{R}^{2}$ value $(0.9942$ and 0.9889$)$ validates the applicability of the pseudo-second-order rate kinetics to the adsorption of $\mathrm{Cr}(\mathrm{VI})$ and $\mathrm{CR}$ dye on the PMC materials.

\subsubsection{Equilibrium study and adsorption isotherms}

Figure. 7 shows the solid phase equilibrium concentrations of $\mathrm{Cr}(\mathrm{VI})$ and CR-dye for different aqueous phase concentrations. The adsorption capacity of the PMC material for $\mathrm{Cr}(\mathrm{VI})$ and $\mathrm{CR}$ was determined at $35^{\circ} \mathrm{C}$ in the aqueous phase concentration range of $10-150$ and $10-800 \mathrm{mgL}^{-1}$ respectively. The adsorption capacity reached equilibrium with increasing aqueous phase 
concentrations. The Langmuir and Freundlich isotherm was used in the linearized form to fit the equilibrium data:

$$
\begin{aligned}
& q e=\frac{q \max K C e}{1+K C e} \\
& Q e=K f C e^{1 / n}
\end{aligned}
$$

Where qe is the solute loading (mg/g) at equilibrium, qmax is the maximum adsorption loading $(\mathrm{mg} / \mathrm{g}), \mathrm{Ce}$ is the equilibrium concentration $(\mathrm{mg} / \mathrm{L})$ and $\mathrm{K}$ is the Langmuir constant. The Langmuir model assumes monolayer coverage of adsorbed molecule over adsorbent however Freundlich model assumes adsorbed molecules have heterogeneous adsorption sites and the adsorbed molecules or ions have a mutual effect on each other. As shown in Figure. 7, the linearized form of the Langmuir equation fits the data for PMC material reasonably well, indicating the monolayer surface coverage of the $\mathrm{Cr}(\mathrm{VI})$ and $\mathrm{CR}$ on PMC material. The maximum adsorption for $\mathrm{Cr}(\mathrm{VI})$ and CR were 76.9 and $714 \mathrm{mg} / \mathrm{g}$ calculated from Langmuir isotherm after $24 \mathrm{~h}$ of equilibrium at 150 $\mathrm{mg} / \mathrm{L}$ and $800 \mathrm{mg} / \mathrm{L}$ of initial concentration showing the applicability of PMC material for $\mathrm{Cr}(\mathrm{VI})$ and CR-dye. Table. 2 lists the numerical values of the Langmuir and Freundlich adsorption constant and the regression correlation coefficient. The values of $\mathrm{K}_{\mathrm{L}}$ range within 0 to 1 , which demonstrates that the samples have a better absorption for $\mathrm{Cr}(\mathrm{VI})$ ions and CR-dye.

\subsubsection{Effect of temperature and thermodynamics of $\mathrm{Cr}(\mathrm{VI})$ and $\mathrm{CR}$ adsorption}

Effect of temperature on $\mathrm{Cr}(\mathrm{VI})$ and $\mathrm{CR}$-dye adsorption on PMC material was studied at three different temperatures viz., 298, 308, and $318 \mathrm{~K}$ with keeping rest parameters constant. Figure. 8 describes the effect of temperature on adsorption. It can be observed from the figure that the maximum adsorption capacity decreased with increasing adsorption temperature, indicating the 
adsorption to be exothermic. Table. 3 shows the calculated values of different parameters from the Langmuir isotherm equation at 298,308 , and $318 \mathrm{~K}$.

Calculations were performed to extract the thermodynamic parameters from the batch data. It was also necessary to conclude whether the adsorption process was exothermic and spontaneous. The thermodynamic parameters, namely Gibb's free energy change $\left(\Delta \mathrm{G}^{\circ}\right)$, enthalpy change $\left(\Delta \mathrm{H}^{\circ}\right)$, and entropy changes $\left(\Delta \mathrm{S}^{\circ}\right)$, were calculated using the following equations:

$$
\begin{aligned}
& -R T \ln K=\Delta \mathrm{G} \\
& \Delta H^{\circ}-T \Delta \mathrm{S}^{\circ}=\Delta \mathrm{G}^{\circ} \\
& \frac{\Delta \mathrm{H}^{\circ}}{R T} \times \frac{\Delta \mathrm{S}^{\circ}}{R}=\ln K
\end{aligned}
$$

Where $\mathrm{R}$ is the gas constant, and $\mathrm{T}$ is the temperature $(\mathrm{K}) . \Delta \mathrm{G}^{\circ}$ was calculated from the $\mathrm{K}$ obtained from the Langmuir equation. Table. 3 lists the numerical values of $\Delta \mathrm{G}^{\circ}$ obtained for different temperatures for $\mathrm{Cr}(\mathrm{VI})$ and $\mathrm{CR}$.

The negative value of $\Delta \mathrm{G}^{\circ}$ describes the spontaneous nature of adsorption for both $\mathrm{Cr}(\mathrm{VI})$ and $\mathrm{CR}$ dye. On increasing the temperature, $\Delta \mathrm{G}^{\circ}$ decreased, indicating that a relatively lower temperature was unfavorable for adsorption. Figure 7 shows the plot of $\operatorname{lnK}$ vs. 1/T and is found to be linear. $\Delta \mathrm{H}^{\circ}$ was calculated to be -37.56 and $-35.4 \mathrm{~kJ} / \mathrm{mole}$ from the slope of the line (Eq. (7)) for $\mathrm{Cr}(\mathrm{VI})$ and $\mathrm{CR}$ dye, confirming the adsorption of $\mathrm{Cr}(\mathrm{VI})$ was exothermic respectively.

\subsubsection{Effect of $\mathrm{pH}$ on $\mathrm{Cr}(\mathrm{VI})$ and $\mathrm{CR}$ dye adsorption}

Figure. 9 shows the effect of $\mathrm{pH}$ on adsorption of $\mathrm{Cr}(\mathrm{VI})$ and $\mathrm{CR}$ dye on PMC based adsorbent material. Figure. 9(a) it is visible that on changing the $\mathrm{pH}$ value from 2 to 9 , adsorption of $\mathrm{Cr}$ (VI) was significantly affected and the highest adsorption loading $(87.5 \mathrm{mg} / \mathrm{g})$ was observed at $\mathrm{pH} \sim 2$. 
The reason for this adsorption capacity is thought to be that the adsorption sites occupy the anionic species, such as $\mathrm{HCrO}_{4}^{-}, \mathrm{CrO}_{4}^{-2}$, and $\mathrm{Cr}_{2} \mathrm{O}_{7}^{-2}$, as the surface of PMC was supposed to be a positive surface charge due to the presence of $\mathrm{Cu}$ ions. In the acid medium with $\mathrm{pH}$ ranging from 1.0 to $4.0, \mathrm{HCrO}_{4}{ }^{-}$is the major species of $\mathrm{Cr}(\mathrm{VI})$, and the surface of PMC was surrounded by adequate $\mathrm{H}^{+}$. Therefore, the amine groups from the chitosan moiety of the adsorbent were easily protonated and positively charged, which promoted the approach of negatively charged $\mathrm{Cr}(\mathrm{VI})$ species $\left(\mathrm{HCrO}_{4}^{-}\right)$attributed to the electrostatic interaction ${ }^{37}$. However, basic $\mathrm{pH}$ exhibits the opposite mechanism as repulsion was the predominant force to expel $\mathrm{Cr}(\mathrm{VI})$ far away from the adsorbent surface subsequently low adsorption capacity.

Similarly, the effect of $\mathrm{pH}$ on adsorption of $\mathrm{CR}$ dye was shown in Figure. 9(b). The maximum loading was observed at $\mathrm{pH} 7(17.84 \mathrm{mg} / \mathrm{g})$ in $10 \mathrm{mgL}^{-1}$ of $\mathrm{CR}$ concentration. The reason behind that as it is well known that $\mathrm{CR}$ is an acidic dye and in the neutral condition. It exists in the anionic form in solution. Additionally, in PMC the surface of aminated graphene (chitosan encapsulated graphene) is positive. It can be expected that the total surface charge over the PMC probably positive during this stage, which gives rise to electrostatic attraction. Therefore, adsorption ability is higher at this $\mathrm{pH}$. However, the acidic $\mathrm{pH}$ of dye solution gives rise to repulsion between adsorbent and adsorbate surface due to similar polarity over CR molecule and surface of PMC. On further increasing the $\mathrm{pH}$ above 7.0, excessive $\mathrm{OH}$ ions compete with the sulfonate groups of $\mathrm{CR}$ and the active site for dye adsorption is reduced compared to neutral $\mathrm{pH}$ which decreases the overall adsorption of CR dye onto PMC based adsorbent material ${ }^{38}$. Therefore, the prepared PMC based adsorbent materials effectively remove both contaminants (Cr(VI) and CR-dye) from water. 


\subsection{Antibacterial activity}

The antimicrobial behavior of different weights $(0.01$ to $0.20 \mathrm{~g})$ of PMC materials was tested against both Gram-negative (E. Coli) and positive (S.aureus) bacterial strains with different exposure times (3-24 h). Figure 10a and 10b show the antibacterial analysis of PMC against both E. Coli and S.aureus, respectively. There were numerous significant observations. (1) PMC materials had suppression or inhibitory effects against both E. Coli and S.aureusbacterial strains. (2) PMC materials have comparatively higher performance against S.aureus bacterial strain. (3) The concentration at or below $0.10 \mathrm{~g}$ of the PMC sample, the E. Coli and S.aureus bacterial colonies were suppressed or inhibited for lesser exposure time ( $3 \mathrm{~h}$ ), and $12 \mathrm{~h}$, respectively, and (4) the higher concentration at $0.20 \mathrm{~g}$ was sufficient to kill or inhibit both bacterial strains at $3 \mathrm{~h}$.

Table. 4 shows the comparative data of the different hybrid materials used for the removal of contaminants from water. The data suggested that the prepared materials have superior adsorption loading among all of them. Moreover, most of the materials can remove either chemical or biological contaminants from water. In this context, the prepared PMC based adsorbent materials or filter has the potential ability to remove both chemical and biological contaminants from water, thereby PMC based adsorbent materials or filter efficiently used for the treatment of water.

\section{Conclusion}

The PMC framework has synthesized using the CBD process and applied as complete decontamination including chemical and biological contaminants from wastewater. The synthesized framework exhibits excellent adsorption towards $\mathrm{Cr}$ (VI) and CR-dye as chemical contaminants and E. coli and $S$. aureus as biological contaminates. The maximum adsorption 
capacity was found to be $76.5 \mathrm{mg} / \mathrm{g}$ and $714 \mathrm{mg} / \mathrm{g}$ for $\mathrm{Cr}(\mathrm{VI})$ and CR-dye, respectively. Pseudosecond-order kinetic model was the best-demonstrated model on the adsorption process. Langmuir and Freundlich's isotherms were the best-fitted models for $\mathrm{Cr}(\mathrm{VI})$ and $\mathrm{CR}$ adsorption on the PMC framework. $\mathrm{pH}$ plays a significant role in the adsorption process as acidic $\mathrm{pH}$ was best for $\mathrm{Cr}(\mathrm{VI})$ adsorption while neutral $\mathrm{pH}$ was the best $\mathrm{pH}$ for $\mathrm{CR}$ adsorption. Surface charge plays important role in the adsorption process as postulated mechanism proves the electrostatic attraction due to adsorbent charges. The as-prepared hierarchical PMC framework is promising adsorbents for the removal of both biological and chemical contaminants from wastewater because of high surface charge, simple synthesis process, and excellent efficiency towards contaminants.

\section{References}

1 Talreja, N., Kumar, D. \& Verma, N. Removal of hexavalent chromium from water using Fe-grown carbon nanofibers containing porous carbon microbeads. Journal of Water Process Engineering 3, 34-45, doi:https://doi.org/10.1016/j.jwpe.2014.08.001 (2014).

2 Çelebi, H., Gök, G. \& Gök, O. Adsorption capability of brewed tea waste in waters containing toxic lead(II), cadmium (II), nickel (II), and zinc(II) heavy metal ions. Scientific Reports 10, 17570, doi:10.1038/s41598-020-74553-4 (2020).

3 Egbosiuba, T. C. et al. Adsorption of $\mathrm{Cr}(\mathrm{VI}), \mathrm{Ni}(\mathrm{II}), \mathrm{Fe}(\mathrm{II})$ and $\mathrm{Cd}(\mathrm{II})$ ions by KIAgNPs decorated MWCNTs in a batch and fixed bed process. Scientific Reports 11, 75, doi:10.1038/s41598-02079857-z (2021).

$4 \quad$ Zhang, W. et al. Enhanced heavy metal removal from an aqueous environment using an ecofriendly and sustainable adsorbent. Scientific Reports 10, 16453, doi:10.1038/s41598-020-73570-7 (2020).

$5 \quad K u m a r, V$. et al. Development of bi-metal doped micro- and nano multi-functional polymeric adsorbents for the removal of fluoride and arsenic(V) from wastewater. Desalination 282, 27-38, doi:https://doi.org/10.1016/j.desal.2011.05.013 (2011).

6 Manisalidis, I., Stavropoulou, E., Stavropoulos, A. \& Bezirtzoglou, E. Environmental and Health Impacts of Air Pollution: A Review. Frontiers in public health 8, 14-14, doi:10.3389/fpubh.2020.00014 (2020).

7 Piccin, J. S., Feris, L. A., Cooper, M. \& Gutterres, M. Dye Adsorption by Leather Waste: Mechanism Diffusion, Nature Studies, and Thermodynamic Data. Journal of Chemical \& Engineering Data 58, 873-882, doi:10.1021/je301076n (2013). 

activated carbon developed from waste rubber tires. Environmental Science and Pollution Research 20, 1261-1268, doi:10.1007/s11356-012-0950-9 (2013).

9 Tor, A. \& Cengeloglu, Y. Removal of congo red from aqueous solution by adsorption onto acid activated red mud. Journal of Hazardous Materials 138, 409-415, doi:https://doi.org/10.1016/j.jhazmat.2006.04.063 (2006).

10 Bhat, S. A. et al. Efficient removal of Congo red dye from aqueous solution by adsorbent films of polyvinyl alcohol/melamine-formaldehyde composite and bactericidal effects. Journal of Cleaner Production 255, 120062, doi:https://doi.org/10.1016/j.jclepro.2020.120062 (2020).

11 Radoor, S., Karayil, J., Parameswaranpillai, J. \& Siengchin, S. Removal of anionic dye Congo red from aqueous environment using polyvinyl alcohol/sodium alginate/ZSM-5 zeolite membrane. Scientific Reports 10, 15452, doi:10.1038/s41598-020-72398-5 (2020).

12 Ashfaq, M., Verma, N. \& Khan, S. Copper/zinc bimetal nanoparticles-dispersed carbon nanofibers: A novel potential antibiotic material. Materials Science and Engineering: C 59, 938-947, doi:https://doi.org/10.1016/j.msec.2015.10.079(2016).

13 Chauhan, D., Afreen, S., Mishra, S. \& Sankararamakrishnan, N. Synthesis, characterization and application of zinc augmented aminated PAN nanofibers towards decontamination of chemical and biological contaminants. Journal of Industrial and Engineering Chemistry 55, 50-64, doi:https://doi.org/10.1016/j.jiec.2017.06.027 (2017).

14 Talreja, N., Verma, N. \& Kumar, D. Carbon Bead-Supported Ethylene Diamine-Functionalized Carbon Nanofibers: An Efficient Adsorbent for Salicylic Acid. CLEAN - Soil, Air, Water 44, 14611470, doi:https://doi.org/10.1002/clen.201500722 (2016).

15 Robinson, T. Removal of toxic metals during biological treatment of landfill leachates. Waste Management 63, 299-309, doi:https://doi.org/10.1016/j.wasman.2016.12.032 (2017).

16 Nur-E-Alam, M., Mia, M. A. S., Ahmad, F. \& Rahman, M. M. An overview of chromium removal techniques from tannery effluent. Applied Water Science 10, 205, doi:10.1007/s13201-020-012860 (2020).

17 Samani, M. R. \& Toghraie, D. Removal of hexavalent chromium from water using polyaniline/ wood sawdust/ poly ethylene glycol composite: an experimental study. Journal of environmental health science \& engineering 17, 53-62, doi:10.1007/s40201-018-00325-y (2019).

18 Thao, V. D., Giang, B. L. \& Thu, T. V. Free-standing polypyrrole/polyaniline composite film fabricated by interfacial polymerization at the vapor/liquid interface for enhanced hexavalent chromium adsorption. RSC Advances 9, 5445-5452, doi:10.1039/c8ra10478f (2019).

19 Stejskal, J. et al. Polyaniline Cryogels Supported with Poly(vinyl alcohol): Soft and Conducting. Macromolecules 50, 972-978, doi:10.1021/acs.macromol.6b02526 (2017).

20 Sankararamakrishnan, N., Shankhwar, A. \& Chauhan, D. Mechanistic insights on immobilization and decontamination of hexavalent chromium onto nano MgS/FeS doped cellulose nanofibres. Chemosphere 228, 390-397, doi:https://doi.org/10.1016/j.chemosphere.2019.04.166 (2019).

21 Mahmoodi, N. M., Salehi, R., Arami, M. \& Bahrami, H. Dye removal from colored textile wastewater using chitosan in binary systems. Desalination 267, 64-72, doi:https://doi.org/10.1016/j.desal.2010.09.007 (2011).

22 Crini, G. \& Badot, P.-M. Application of chitosan, a natural aminopolysaccharide, for dye removal from aqueous solutions by adsorption processes using batch studies: A review of recent literature. Progress in Polymer Science 33, 399-447, doi:https://doi.org/10.1016/j.progpolymsci.2007.11.001 (2008).

23 Croisier, F. \& Jérôme, C. Chitosan-based biomaterials for tissue engineering. European Polymer Journal 49, 780-792, doi:https://doi.org/10.1016/j.eurpolymj.2012.12.009 (2013). 
Tripathi, K. M., Tyagi, A., Ashfaq, M. \& Gupta, R. K. Temperature dependent, shape variant synthesis of photoluminescent and biocompatible carbon nanostructures from almond husk for applications in dye removal. RSC Advances 6, 29545-29553, doi:10.1039/c5ra27432j (2016).

Kumar, D. \& Talreja, N. Nickel nanoparticles-doped rhodamine grafted carbon nanofibers as colorimetric probe: Naked eye detection and highly sensitive measurement of aqueous $\mathrm{Cr} 3+$ and $\mathrm{Pb2+}$. Korean Journal of Chemical Engineering 36, 126-135, doi:10.1007/s11814-018-0139-0 (2019).

26 Homaeigohar, S. \& Elbahri, M. Graphene membranes for water desalination. NPG Asia Materials 9, e427-e427, doi:10.1038/am.2017.135 (2017).

27 Ashfaq, M., Khan, S. \& Verma, N. Synthesis of PVA-CAP-based biomaterial in situ dispersed with Cu nanoparticles and carbon micro-nanofibers for antibiotic drug delivery applications. Biochemical Engineering Journal 90, 79-89, doi:https://doi.org/10.1016/j.bej.2014.05.016 (2014).

28 Ashfaq, M., Verma, N. \& Khan, S. Highly effective Cu/Zn-carbon micro/nanofiber-polymer nanocomposite-based wound dressing biomaterial against the $P$. aeruginosa multi-and extensively drug-resistant strains. Materials Science and Engineering: C 77, 630-641, doi:https://doi.org/10.1016/j.msec.2017.03.187 (2017).

29 Mohamed, N. A., Al-Harby, N. F. \& Almarshed, M. S. Enhancement of adsorption of Congo red dye onto novel antimicrobial trimellitic anhydride isothiocyanate-cross-linked chitosan hydrogels. Polymer Bulletin 77, 6135-6160, doi:10.1007/s00289-019-03058-6 (2020).

30 Singh, P. \& Nagendran, R. A comparative study of sorption of chromium (III) onto chitin and chitosan. Applied Water Science 6, 199-204, doi:10.1007/s13201-014-0218-2 (2016).

31 Ashfaq, M., Singh, S., Sharma, A. \& Verma, N. Cytotoxic Evaluation of the Hierarchical Web of Carbon Micronanofibers. Industrial \& Engineering Chemistry Research 52, 4672-4682, doi:10.1021/ie303273s (2013).

32 Strankowski, M., Włodarczyk, D., Piszczyk, Ł. \& Strankowska, J. Polyurethane Nanocomposites Containing Reduced Graphene Oxide, FTIR, Raman, and XRD Studies. Journal of Spectroscopy 2016, 7520741, doi:10.1155/2016/7520741 (2016).

33 Gokila, S., Gomathi, T., Sudha, P. N. \& Anil, S. Removal of the heavy metal ion chromiuim(VI) using Chitosan and Alginate nanocomposites. International Journal of Biological Macromolecules 104, 1459-1468, doi:https://doi.org/10.1016/j.ijbiomac.2017.05.117 (2017).

34 Hatchett, D. W., Kodippili, G., Kinyanjui, J. M., Benincasa, F. \& Sapochak, L. FTIR analysis of thermally processed PU foam. Polymer Degradation and Stability 87, 555-561, doi:https://doi.org/10.1016/j.polymdegradstab.2004.10.012 (2005).

35 Dubal, D. P., Dhawale, D. S., Salunkhe, R. R., Jamdade, V. S. \& Lokhande, C. D. Fabrication of copper oxide multilayer nanosheets for supercapacitor application. Journal of Alloys and Compounds 492, 26-30, doi:https://doi.org/10.1016/j.jallcom.2009.11.149 (2010).

36 Wang, X., Tang, R., Zhang, Y., Yu, Z. \& Qi, C. Preparation of a Novel Chitosan Based Biopolymer Dye and Application in Wood Dyeing. Polymers 8, doi:10.3390/polym8090338 (2016).

37 Liu, H., Zhang, F. \& Peng, Z. Adsorption mechanism of $\mathrm{Cr}(\mathrm{VI})$ onto GO/PAMAMs composites. Scientific Reports 9, 3663, doi:10.1038/s41598-019-40344-9 (2019).

38 Omidi, S. \& Kakanejadifard, A. Eco-friendly synthesis of graphene-chitosan composite hydrogel as efficient adsorbent for Congo red. RSC Advances 8, 12179-12189, doi:10.1039/c8ra00510a (2018). 
Figures

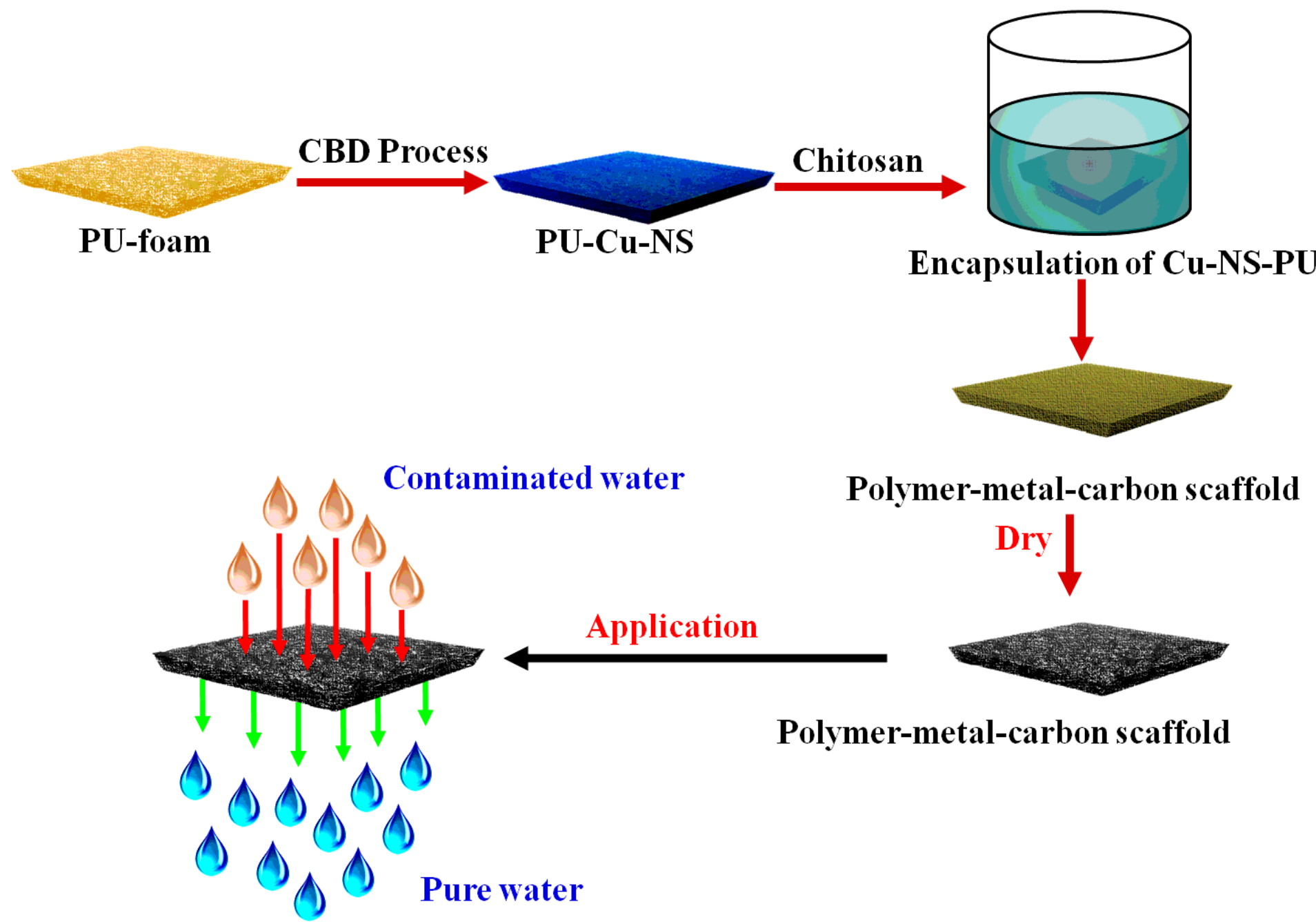

Figure 1

Schematic representation of the synthesis of the PMC framework as filter or adsorbent materials for environmental remediation application. 

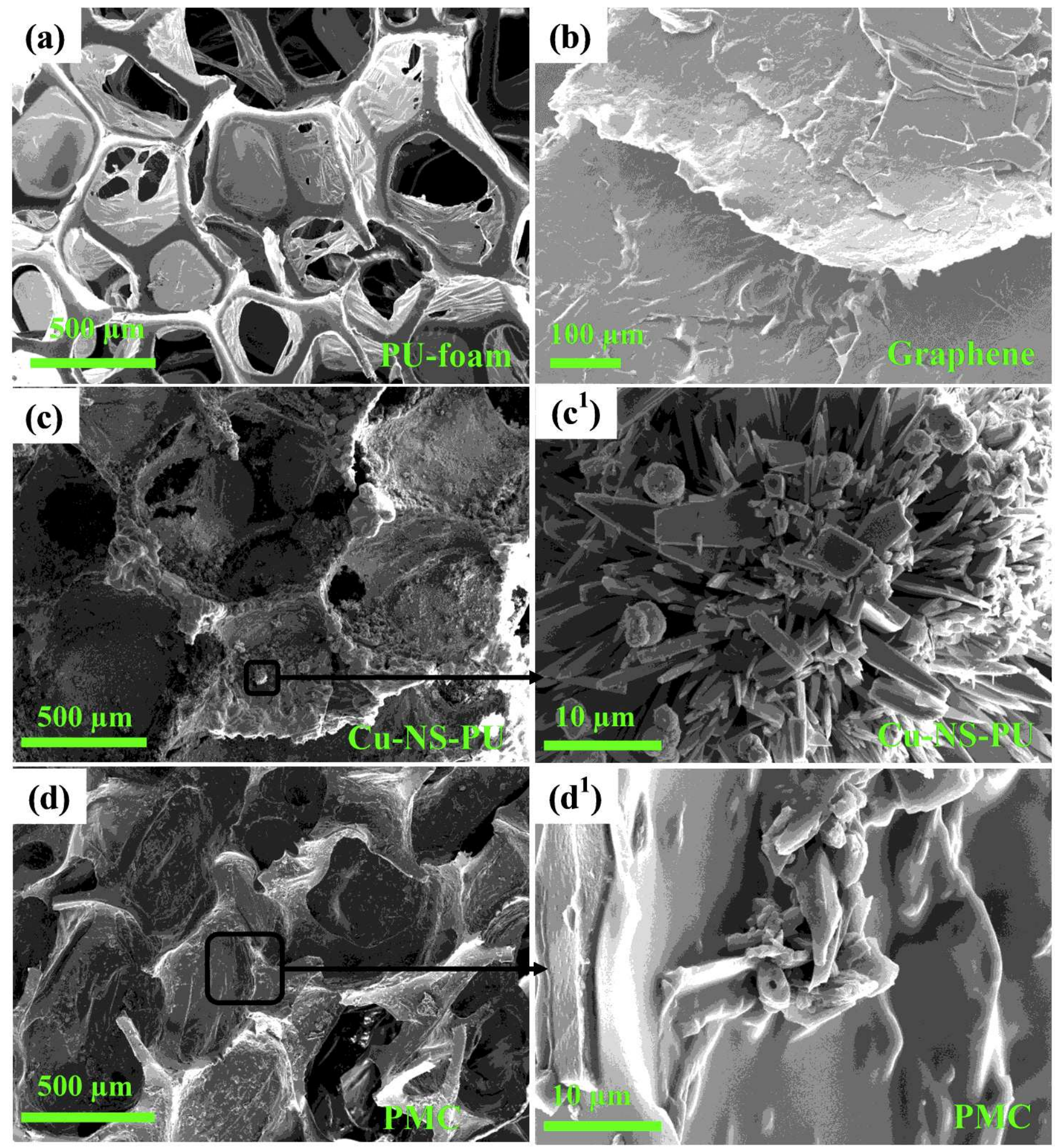

Figure 2

SEM images of (a) PU foam, (b) graphene nanosheet, (c-c') Cu-NS-PU, and (d-d') PMC. 


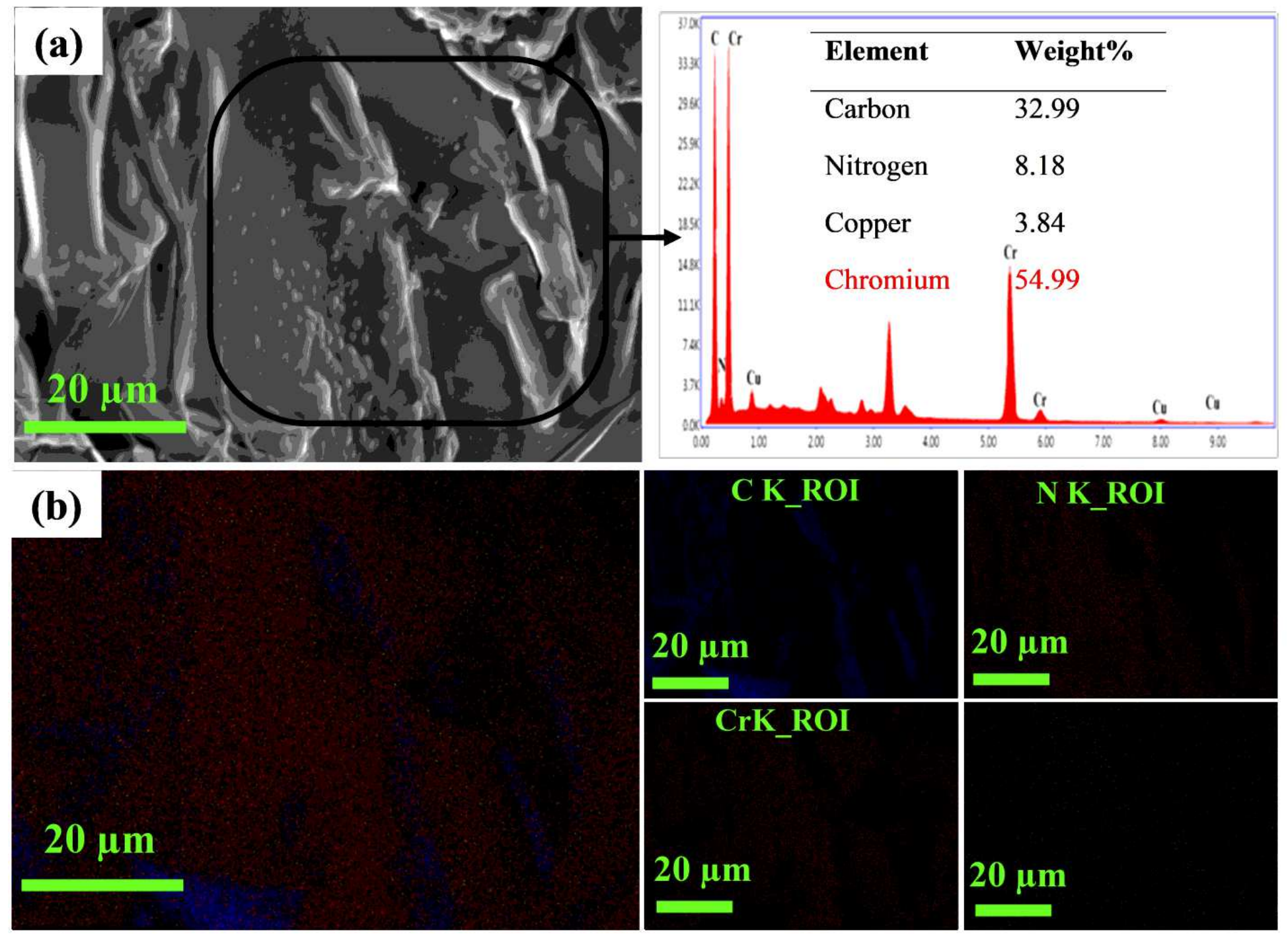

Figure 3

Elemental analysis of the $\mathrm{Cr}$ adsorbed PMC sample (a) elemental analysis, and (b) elemental mapping. 


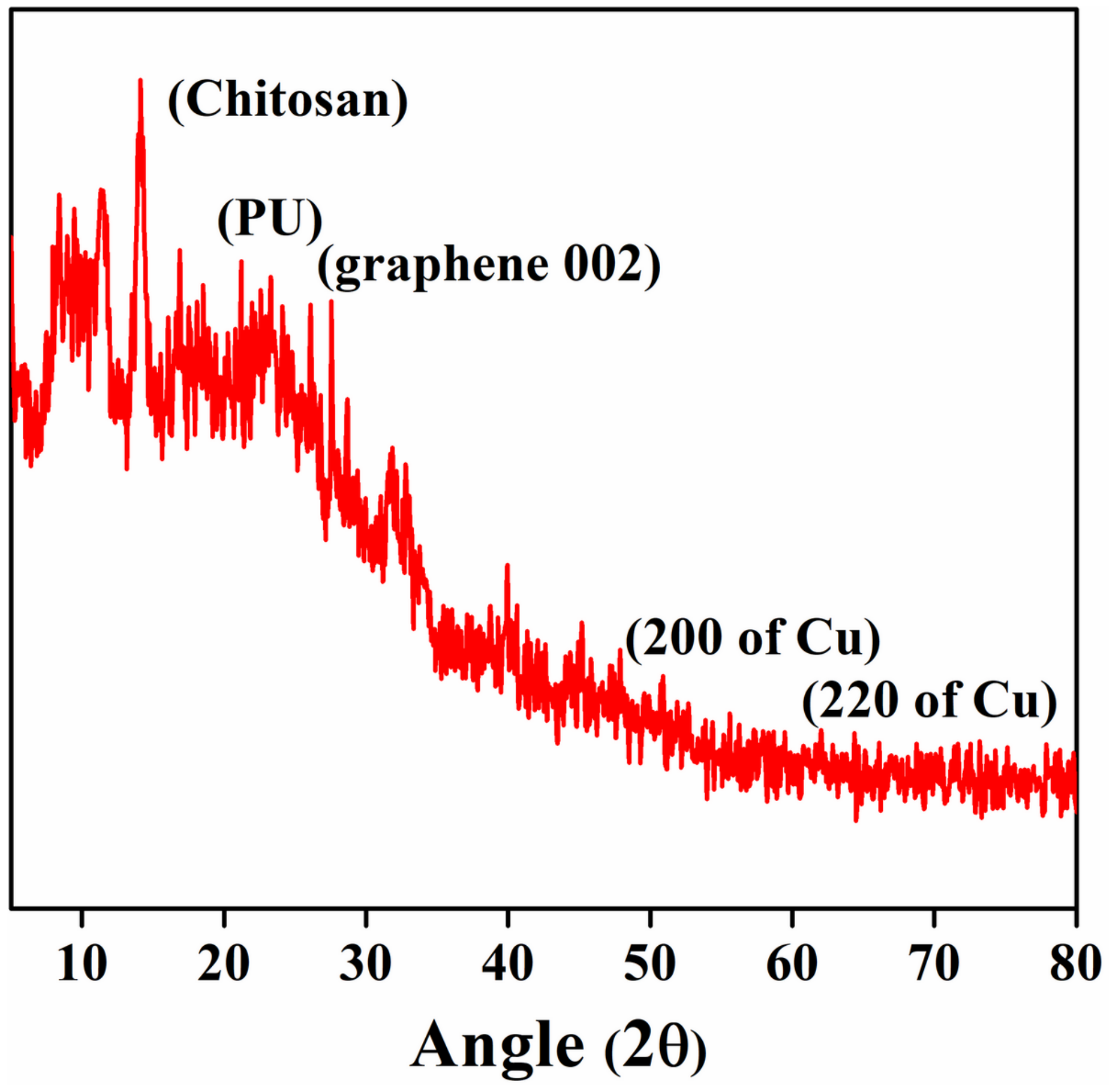

Figure 4

$\mathrm{XRD}$ analysis of the PMC material. 


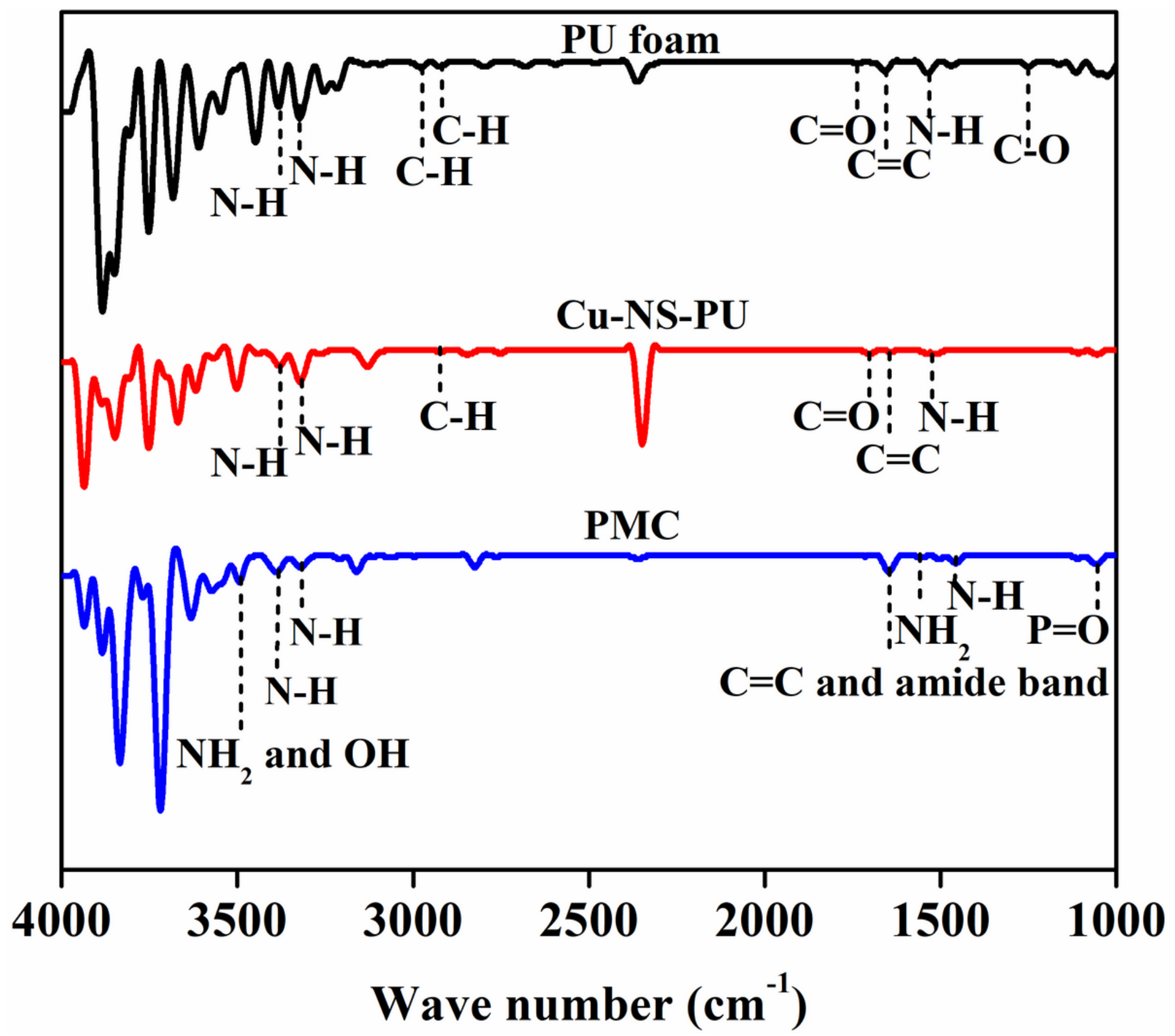

Figure 5

FT-IR spectra of the various constituents of the PMC based material 

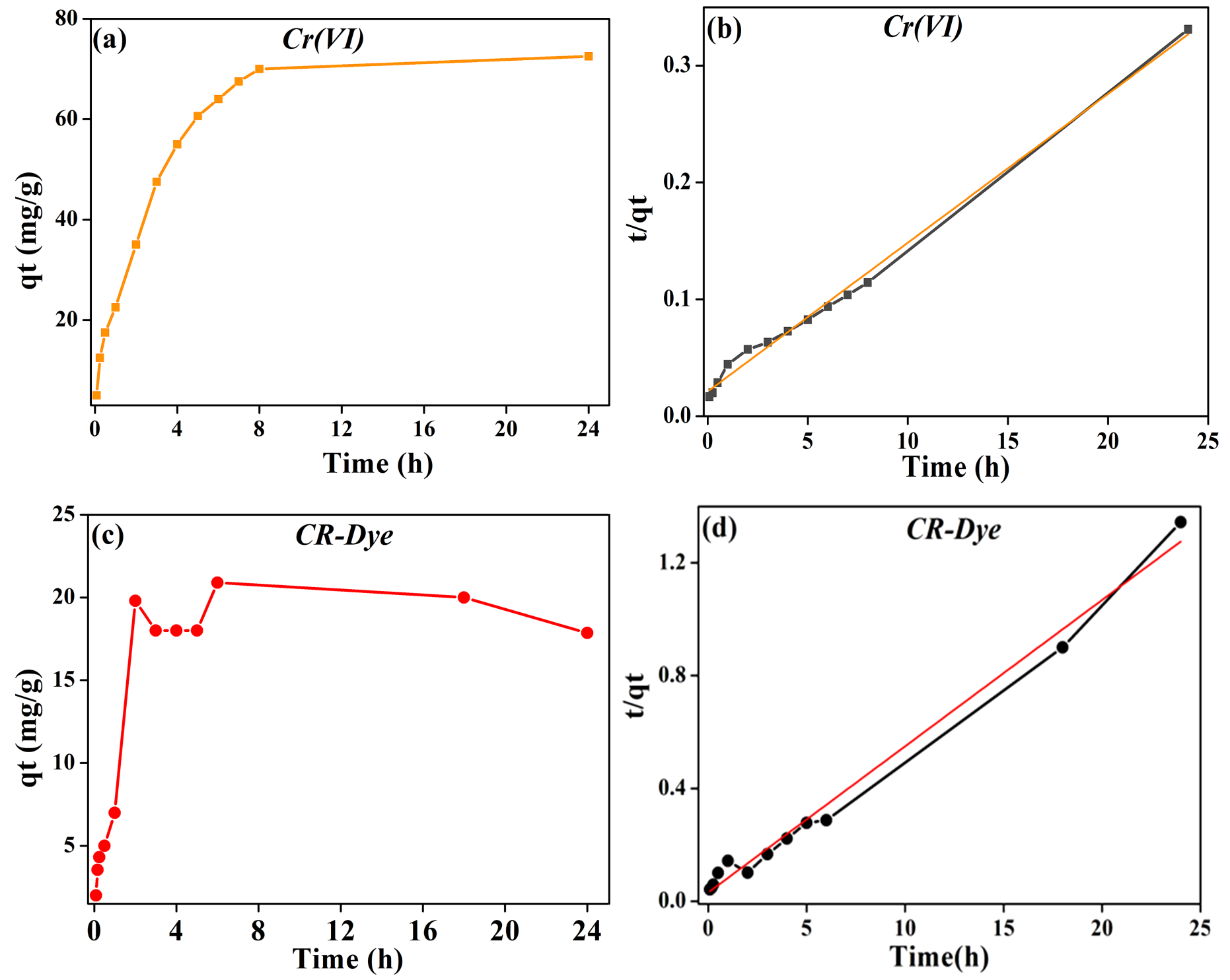

Figure 6

Adsorption kinetics of $\mathrm{Cr}(\mathrm{VI})$, and $\mathrm{CR}$-dye on the prepared PMC based material. (a) Time study of $\mathrm{Cr}(\mathrm{VI})$, (b) pseudo-second-order kinetic model of $\mathrm{Cr}(\mathrm{VI})$, (c) Time study of CR-Dye, and (d) pseudo-second-order kinetic model of CR-Dye. 

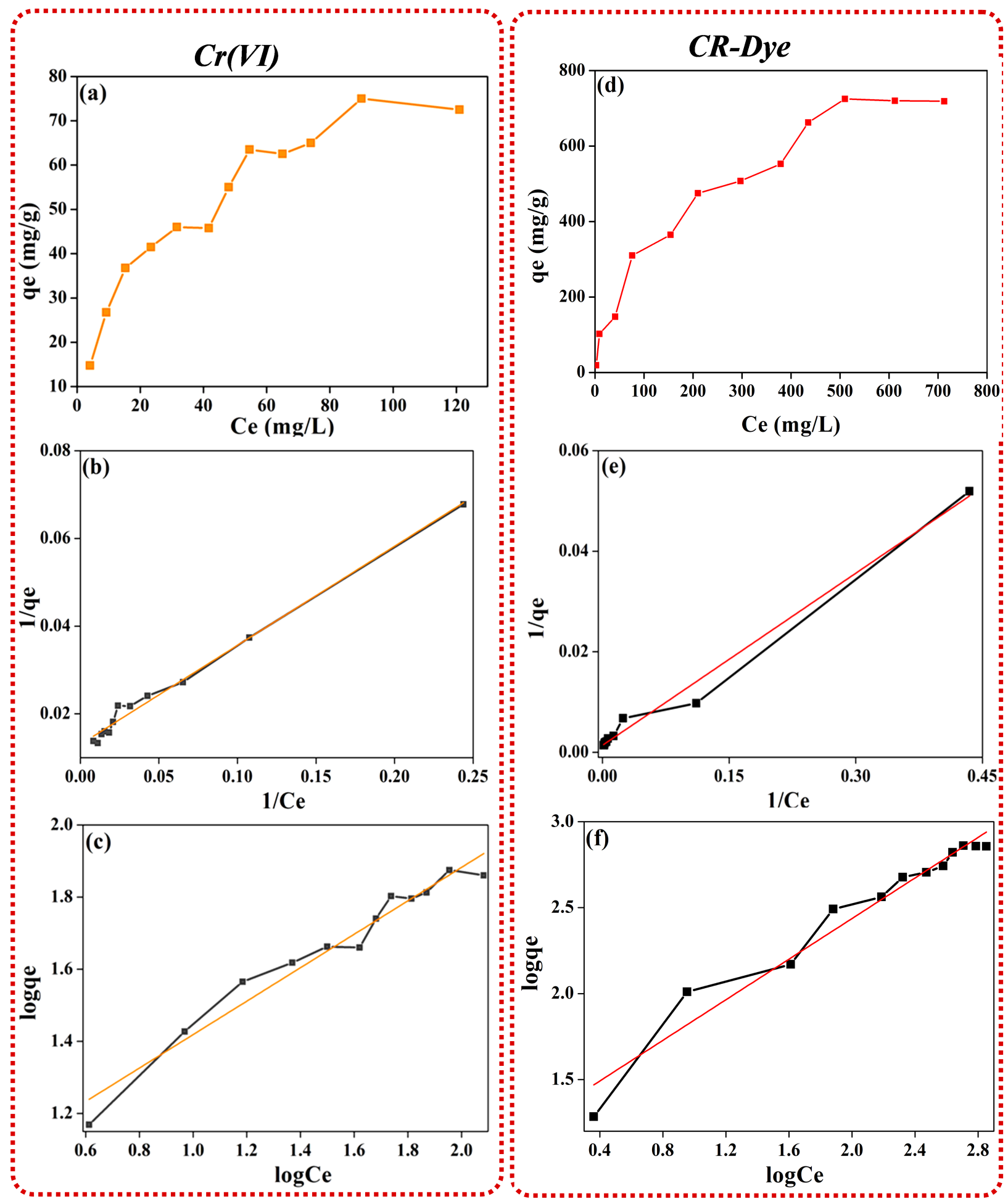

Figure 7

Effect of liquid phase concentration of (a-c) $\mathrm{Cr}(\mathrm{VI})$ adsorption (d-f) CR-dye adsorption. (a). adsorption isotherm, (b). Langmuir isotherm, (c). Freundlich Isotherm, (d). adsorption isotherm, (e). Langmuir isotherm, and (f). Freundlich Isotherm. 

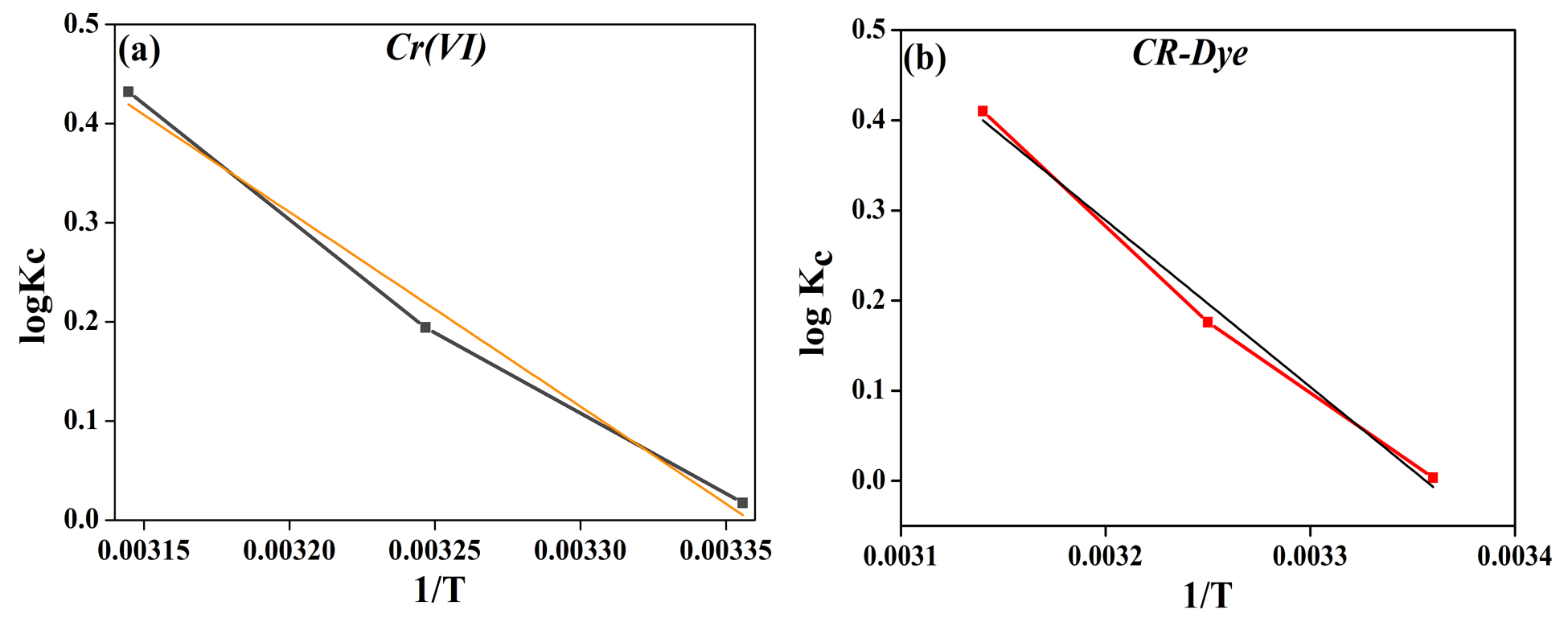

Figure 8

Effect of temperature and thermodynamics. (a) $\mathrm{Cr}(\mathrm{VI})$, and (b) CR-dye.
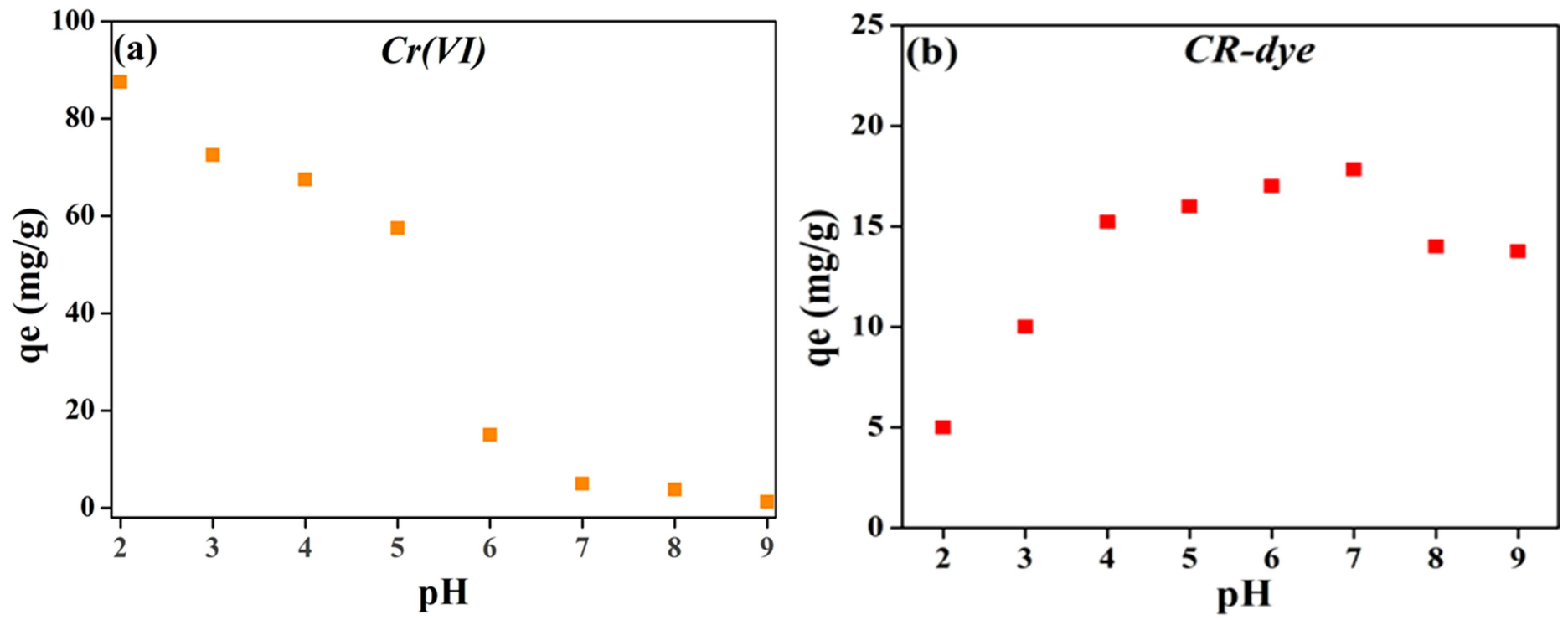

Figure 9

Effect of pH on adsorption of (a) $\mathrm{Cr}(\mathrm{VI})$ (b) CR Dye. 

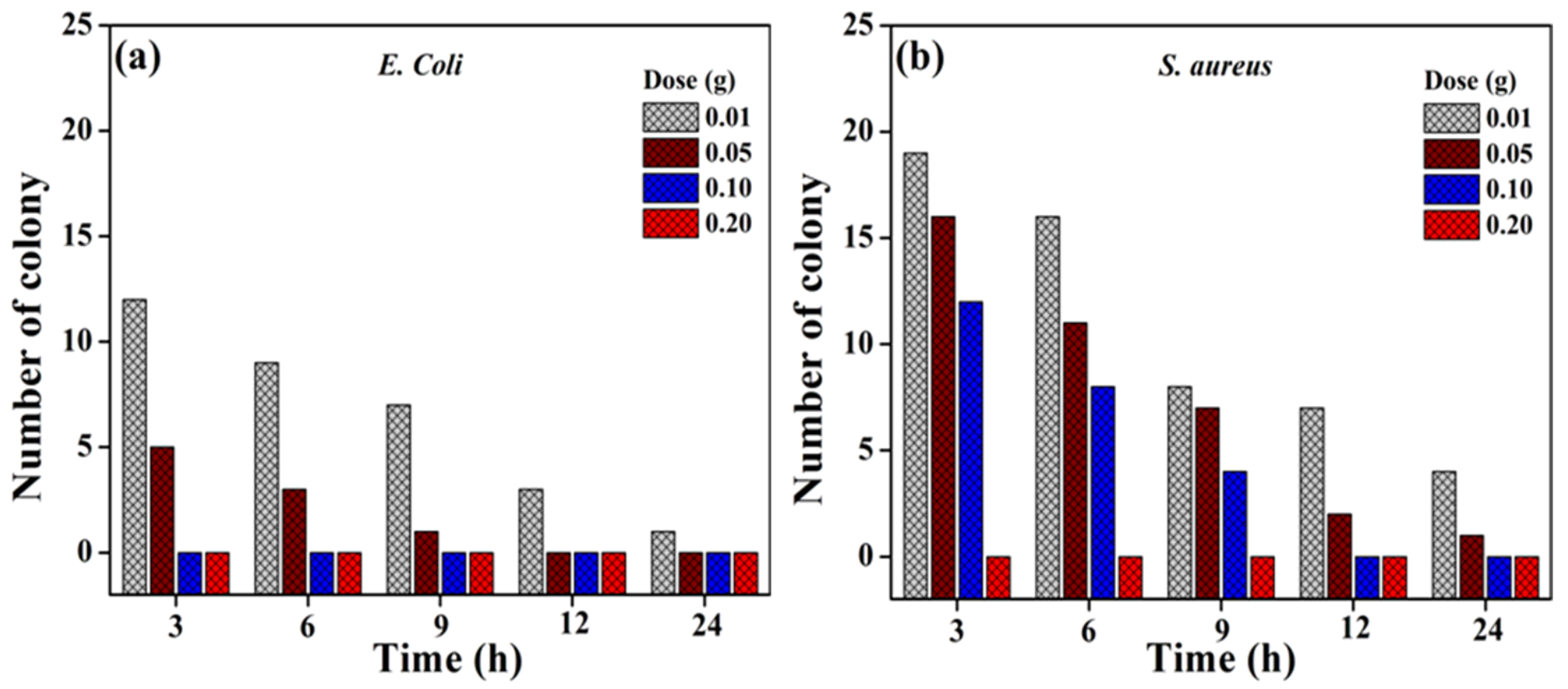

Figure 10

Antibacterial activity of PMC materials against (a) E. Coli, and (b) S. aureus. 